I6 a 18 de outubro de 2019 - Campinas | Brasil

\title{
Impacto das inovações tecnológicas no comércio de livros no Brasil: diversificação de produtos e comércio eletrônico
}

\section{Laís César Guimarães*, Renato de Castro Garcia.}

\section{Resumo}

Este projeto de iniciação científica buscou investigar as inovações no mercado editorial de livros no Brasil e como estas alteraram a dinâmica competitiva desse setor. $O$ foco da pesquisa esteve na análise do comércio virtual e na diversificação de produtos. O estudo foi feito por meio do mapeamento da oferta, análise do setor produtivo e comércio, da demanda, estudo do comportamento do consumidor e da segmentação do mercado, e investigou como as inovações impactam diretamente a atividade do setor.

\section{Palavras-chave:}

mercado de livros, comércio virtual, inovação

\section{Introdução}

Com o surgimento das novas tecnologias digitais, houve uma reorganização da cadeia produtiva do livro e também alterações no varejo. O objetivo deste projeto é investigar as transformações no mercado editorial de livros no Brasil e como estas alteraram a dinâmica competitiva desse setor, principalmente na mudança no canal de vendas do setor tradicional de livrarias físicas para o comércio digital e também na diversificação de produtos, como e-books e audiobooks.

\section{Resultados e Discussão}

Não há um padrão internacional de segmentação do mercado editorial de livros.No Brasil, o mercado é normalmente dividido em: obras gerais (OG); livros didáticos (LD; científicos, técnicos e profissionais (CTP); e religiosos (R). Respectivamente, os valores gerados por esses setores são $27 \%, 37 \%$, 22\% e $14 \%$ do faturamento do mercado.

Em relação a demanda as compras do governo têm destacado papel no segmento LD e destinam-se a atender à demanda da rede pública de ensino médio e fundamental. O Programa Nacional do Livro Didático (PNLD) e o Programa Nacional Biblioteca da Escola (PNBE) respondem por cerca de $23 \%$ das receitas do setor.

\section{Gráfico 1. PIB e Vendas do Mercado}

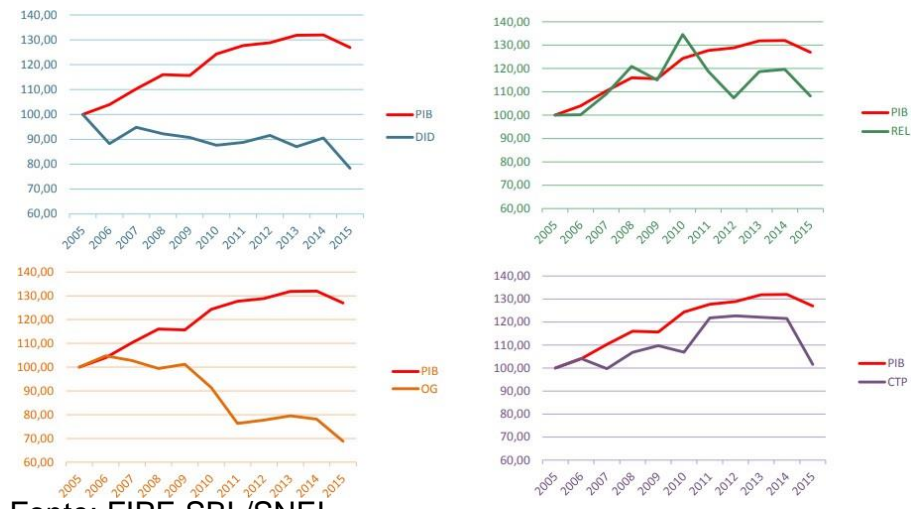

Fonte: FIPE SBL/SNEL

O surgimento de novas tecnologias permitiu que novos atores surgissem na cadeia produtiva do livro, na Figura 1 temos uma esquematização das diferentes etapas desse processo. O antigo modelo é representado pelas linhas contínuas e o novo pelas linhas pontilhadas.
Figura 1. Cadeia produtiva do livro no Brasil

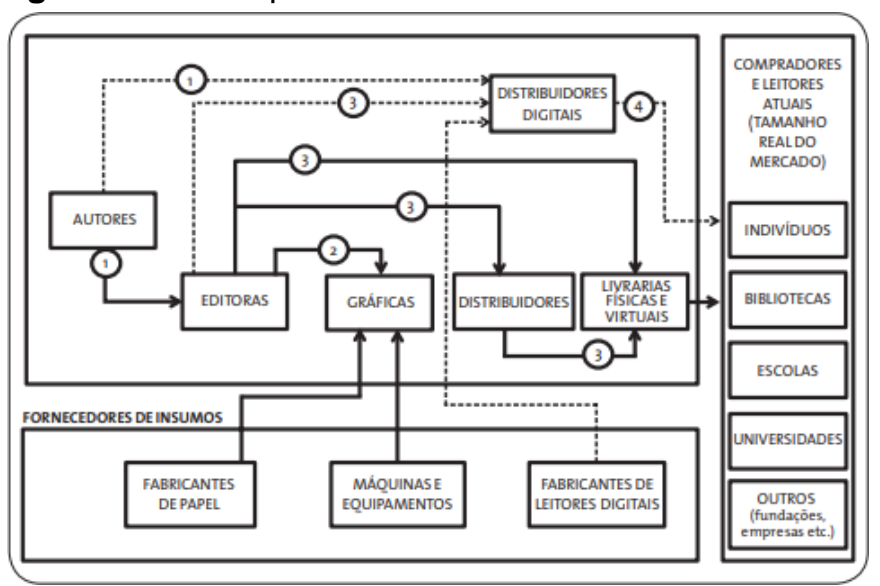

Fonte: Mello et al (2016)

A pesquisa FIPE aponta que em 2018 as livrarias representavam $50 \%$ de participação nas vendas ao mercado, porém em 2017 essa fatia era de 59,5\%. Já as livrarias exclusivamente virtuais apresentaram 3,4\% de participação nas vendas em 2018, sendo que em 2017 esse valor era de $2,5 \%$. A Livraria Saraiva, no primeiro trimestre de 2019 tinha $37,8 \%$ das suas receitas líquidas composta pelo e-commerce.

\section{Conclusões}

O mercado setorial sofreu muito com a recessão e o baixo crescimento econômico dos últimos anos. Obras Gerais corresponde a maior queda de vendas e o setor vem buscando alternativas para reverter essa situação, primeiramente com a redução dos custos e posteriormente com a diversificação de produtos.

As livrarias vem apresentando uma queda na participação de vendas nas suas lojas tradicionais e passam por uma transição para os canais digitais.

\section{Agradecimentos}

Agradecimento especial ao orientador desse projeto Renato Garcia, pela confiança e meu agradecimento ao $\mathrm{PIBIC/CNPq}$ por viabilizar a realização desta pesquisa.

MELLO, G. A. T. Desafios para o setor editorial brasileiro de livros na era digital. BNDES Setorial, Rio de Janeiro, n. 36, p. 468-473, BNDES, set. 2012.

MELLO, et al. Tendências da era digital na cadeia produtiva do livro. BNDES Setorial, Rio de Janeiro, n. 43, p. 41-79, BNDES, mar. 2016.

CBL - CÂMARA BRASILEIRA DO LIVRO/SNEL - SINDICATO NACIONAL DE EDITORES DE LIVROS/FIPE - FUNDAÇÃO INSTITUTO DE PESQUISAS ECONÔMICAS. Produção e vendas do setor editorial brasileiro - 2017. São Paulo, 2018

LIVRARIA SARAIVA. Release de Resultados, 1T19. 2019 